\title{
THERMAL PROPERTIES OF SODIUM-EXCHANGED PALABORA VERMICULITE
}

Hermínio F. Muiambo ${ }^{1,2}$, Walter W. Focke ${ }^{1, *}$, Maria Atanasova ${ }^{3}$, Isbe van der Westhuizen ${ }^{1}$, and Louwrens R. Tiedt ${ }^{4}$

${ }^{1}$ Institute of Applied Materials, Departments of Chemistry and of Chemical Engineering, University of Pretoria, Lynnwood Road, Pretoria 0002, South Africa. E-mail: walter.focke@up.ac.za

${ }^{2}$ Permanent address: Chemistry Department, University Eduardo Mondlane, P.O. Box 257, Maputo, Mozambique.

${ }^{3}$ Council for Geoscience, 280 Pretoria Road, Private Bag X112, Pretoria, South Africa.

${ }^{4}$ Laboratory for Electron Microscopy, North-West University (Potchefstroom Campus), Private Bag X6001, Potchefstroom, 2520. South Africa.

ABSTRACT: Palabora represents an interstratified vermiculite-biotite containing less than $50 \%$ vermiculite. The sodium-exchanged form was prepared by immersion in saturated brine at ambient conditions. The sodium content reached the equilibrium level within the first month of exposure. However, XRD spectra continued to evolve and sharpen over a six month period. The thermal-activated exfoliation was studied using thermo-mechanical analysis. The expansion of the neat "vermiculite" commenced at temperatures above $420{ }^{\circ} \mathrm{C}$. In some applications a lower exfoliation temperature is desirable, i.e. in the range 200 to $350^{\circ} \mathrm{C}$. This study revealed that simple sodium exchange is effective towards this goal as it lowered the onset temperature by about $120^{\circ} \mathrm{C}$. The linear expansion reached a maximum of about eight-fold at temperatures around $700{ }^{\circ} \mathrm{C}$ and decreased again at higher temperatures.

Keywords: Vermiculite; Ion-exchange; Mixed-layer; Interstratification; Exfoliation.

*Corresponding author. Tel.: +27 12420 3728; fax: +27 124202516.

E-mail address: walter.focke@up.ac.za 


\section{INTRODUCTION}

The "vermiculite" of commerce features the desirable property that it expands by more than eight times in volume when heated rapidly to elevated temperatures (Walker, 1961; Wada, 1973a; Wada, 1973b; Friedman et al., 1994; Tomanec et al., 1997). This occurs as a sheet exfoliation process that is driven by an explosive release of interlayer water (Baumeister and Hahn, 1976; Obut and Girgin, 2002). The Palabora mine in the Limpopo province of South Africa is a major source of such commercial "vermiculite”. The exfoliated "vermiculite" is of industrial interest because it is incombustible and lightweight and shows excellent absorption and thermal insulation properties (Wada, 1973b, Schoeman, 1989; Tomanec et al., 1997; Obut and Girgin, 2002; Bergaya et al., 2006). It is used as lightweight aggregate in concretes and plasters (Wada, 1973b; da Silva et al., 2003); as absorbent in water purification, and for controlled release of fertilizers and pesticides (Schoeman, 1989).

Actually Palabora "vermiculite" is not pure vermiculite but rather a mixed-layer vermiculite-biotite (Schwellnus, 1938; Basset, 1963; Schoeman, 1989). In fact, "vermiculite” is a generic name for minerals with characteristics similar to vermiculite (Justo et al., 1989; de Haro et al., 2005). Schoeman (1989) proposed the name hydrophlogopite for the mineral considered presently.

Vermiculite proper is a layered micaceous mineral typically formed by the hydrothermal alteration of mica (Brindley and Brown, 1980; Harben and Roberts, 1990). Palabora "vermiculite" is a product of hydration of phlogopite/biotite under the influence of percolating meteoric water at the weathering surface. During the vermiculization process there is progressive leaching of potassium alkali, an increase in the total water content, a change in color and a simultaneous loss in elasticity and transparency on the part of mica (Basset, 1963; Schoeman, 1989). 
Both biotite and vermiculite are 2:1 clays comprising two tetrahedral silica layers sandwiching an octahedral brucite-like magnesium oxide sheet. The structure is generated by an s-b-s stacking sequence. The layers carry a net negative charge owing to isomorphous substitutions of $\mathrm{Si}$ in the tetrahedral sites by trivalent ions such as $\mathrm{Al}^{3+}$ or $\mathrm{Fe}^{3+}$. However, this is partially compensated by substitution of $\mathrm{Mg}^{2+}$ in the octahedral sites by trivalent ions, e.g. $\mathrm{Fe}^{3+}$. The excess sheet charge is neutralized by alkali-metal or alkaline-earth interlayer cations, e.g. $\mathrm{Mg}^{2+}$, present in the interlayer galleries. In biotite the interlayer ions are potassium and the galleries contain no water. In contrast vermiculite contains the equivalent of up to two sheets of interlayer water.

$$
\begin{array}{r}
\left(\mathrm{Mg}_{3-x} \mathrm{Fe}_{x}^{2+}\right)\left[\mathrm{Si}_{4-y-z} \mathrm{Al}_{y} \mathrm{Fe}_{z}^{3+}\right] \mathrm{O}_{10}(\mathrm{OH})_{2} \mathrm{~K}_{y+z}^{+} \rightarrow \alpha\left(\mathrm{Mg}_{3-x} \mathrm{Fe}_{x}^{2+}\right)\left[\mathrm{Si}_{4-y-z} \mathrm{Al}_{y} \mathrm{Fe}_{z}^{3+}\right] \mathrm{O}_{10}(\mathrm{OH})_{2} \mathrm{~K}_{y+z}^{+} \\
+(1-\alpha)\left(\mathrm{Mg}_{3-x} \mathrm{Fe}_{\mathrm{x}}^{3+}\right)\left[\mathrm{Si}_{4-y-z} \mathrm{Al}_{y} \mathrm{Fe}_{z}^{3+}\right] \mathrm{O}_{10}(\mathrm{OH})_{2} \mathrm{Mg}_{(y+z-x) / 2}^{2+} . n \mathrm{H}_{2} \mathrm{O}
\end{array}
$$

Scheme I: Simplified representation of the partial conversion of biotite into vermiculite (Newman, 1987). It is assumed that Fe(III) is present in the tetrahedral sheets and that the $\mathrm{Fe}(\mathrm{II})$ in the octahedral sheets is completely oxidized during the vermiculization process.

Scheme I illustrated the partial transformation of biotite to vermiculite in a decidedly simplified manner. The process entails the replacement of the interlayer potassium ion by a hydrated cation (usually magnesium and less frequently calcium) and the oxidation of the iron(II) present in the brucite-like layer (Newman, 1987). Thus the net negative charge is lower than that of the parent biotite and usually falls in the range 0.6 to 0.9 per $\mathrm{O}_{10}(\mathrm{OH})_{2}$ unit. The decreased charge density facilitates the stripping of $\mathrm{K}^{+}$ions and their replacement by (most commonly) hydrated $\mathrm{Mg}^{2+}$ ions. The co-intercalation of water increases the gap between the 2:1 layers. The hydration energy of the cation (which is a function of charge 
density and ionic radius) attracts water. A monovalent cation has a lower hydration energy than an equivalent sized divalent cation. The interlayer distance is therefore dependent on the balance of forces necessary to dehydrate the cation and the forces of attraction between the layers and the cation.

During the transformation from mica to vermiculite, numerous intermediate mixed-layer phases with various compositions and ordering are formed. In general, a more ordered structure results when the interlayer space is of higher charge and also when humidity is high enough to give well-bonded water. The regularly interstratified phase containing 50/50 mica/vermiculite (1:1 layer) was described by Gruner (1934) who called it hydrobiotite. It has basal reflections at $2.43 \mathrm{~nm}, 1.223 \mathrm{~nm}, 0.827 \mathrm{~nm}, 0.490 \mathrm{~nm}$ and $0.349 \mathrm{~nm}$ (Brindley et al., 1983). However, the name "hydrobiotite" is not internationally recognized as a valid mineral name, although it has long been used in literature and associated with interstratified biotite/vermiculite minerals found in commercial vermiculite deposits (Boss, 1967; van der Marel and Beutelspacher, 1976; Brindley et al., 1983; Newman, 1987, p. 106; Hudson, 1999; Zhu et al., 2008). Mixed-structure clay minerals with any appreciable degree of randomness show a seemingly irrational series of peaks that makes their identification and interpretation quite a complex exercise. However, computer programs are available for predicting the diffraction patterns of one-dimensional mixed-layer clays (Reynolds, 1985).

Compared to montmorillonite (MMT), chlorite, kaolinite and hydrous micas, vermiculite proper has a higher cation exchange capacity (CEC). Furthermore, the electrostatic charge of the vermiculite layer is heterogeneous due to variations in substitution levels in the layers, and even within the individual layers (de Haro, 2005; Tjong, 2006). Palabora vermiculite, like other commercial types, shows considerable variability in both composition and CEC. This is attributed to differences in the composition of the original parent mica and the degree of progress in the chemical changes induced by weathering (Basset, 1963; Frank, 2001). In 
interstratified vermiculite, the individual flakes are made up of elementary layers of two types, e.g. vermiculite and biotite (MacEwan et al. 1961, Newman, 1987). Unlike the potassium cations in biotite, the hydrated interlayer ions (usually magnesium) in vermiculites are easily exchanged (Newman, 1987). Justo et al. (1993), Ou and Bablouzian (1994) and Marcos et al. (2008) have shown that, compared to pure vermiculite, mica interstratified materials feature higher expansion ratios with the thermal exfoliation also commencing at lower temperatures.

The chemical stability and mineralogical behavior of clay minerals in saline solutions has attracted interest owing to their ability to absorb and immobilize toxic ions derived from radioactive and chemical waste. Most studies focused on the mineralogical and chemical transformation of bentonite in saline water at elevated temperatures (Herbert and Moog, 1999; Herbert et al., 2004; Suzuki et al., 2008). Few investigations considered vermiculite. LopezGonzalez and Cano-Ruiz (1957) and Raman and Jackson (1963) studied the surface morphology of both neat vermiculite and exchanged forms following exposure to alkaline salts and after thermal treatment. Da Fonseca et al. (2005) concluded that vermiculite exhibits good absorption capacity for divalent heavy metal ions from aqueous solutions.

The conventional processes for the manufacture of exfoliated vermiculite employs temperatures exceeding $800{ }^{\circ} \mathrm{C}$. Baumeister and Hahn (1976) found that treatment of vermiculite with $\mathrm{H}_{2} \mathrm{O}_{2}$ leads to exfoliation at temperatures below $100^{\circ} \mathrm{C}$. In some applications, notably intumescent fire barriers, it is desirable that exfoliation of vermiculite should occur at intermediate temperatures, i.e. in the range 200 to $350^{\circ} \mathrm{C}$. Towards this purpose vermiculite was modified with urea, thiourea or ammonium dihydrogen phosphate (Wada, 1973a; Wada, 1973b; Langer and Marlor, 1981). This study reveals that exposing Palabora vermiculite to saturated sodium chloride solution at ambient conditions leads to a similar result. 


\section{EXPERIMENTAL: STARTING MATERIALS AND TECHNIQUES}

Mandoval Vermiculite supplied samples of milled Palabora material. The Superfine (1 $\mathrm{mm})$ and Micron $(0.5 \mathrm{~mm})$ grades ostensibly differed in flake size only. The sodium exchange reaction was performed over a period of six months in closed containers containing the “vermiculite” (5 kg) submerged in a large volume of saturated sodium chloride solution (15 L). The suspension was agitated daily. Every fortnight approximately $10 \mathrm{~L}$ of the supernatant liquid was exchanged with fresh saturated brine. At the end of every month, vermiculite samples (ca. $100 \mathrm{~g}$ ) were taken for analysis. They were rinsed with distilled water and allowed to air-dry at ambient conditions.

Chemical composition was determined by X-ray fluorescence (XRF) method. For major element analysis a milled sample $(<75 \mu \mathrm{m})$ of the neat or exchanged material was roasted at $1000^{\circ} \mathrm{C}$ for at least 3 hours to oxidize $\mathrm{Fe}^{2+}$ and $\mathrm{S}$ and to determine the loss of ignition (L.O.I.). Glass disks were prepared by fusing $1 \mathrm{~g}$ roasted sample and $8 \mathrm{~g}$ of a flux (consisting of $35 \% \mathrm{LiBO}_{2}$ and $64.71 \% \mathrm{Li}_{2} \mathrm{~B}_{4} \mathrm{O}_{7}$ ) at $1050{ }^{\circ} \mathrm{C}$. The glass disks were analyzed by a PANalytical Axios X-ray fluorescence spectrometer equipped with a $4 \mathrm{~kW}$ Rh tube.

Interlayer composition was studied using ammonium acetate $\left(\mathrm{NH}_{4} \mathrm{OOCCH} 3\right)$ method (Schollenberger, and Simon, 1945; Barshad, 1954a; Barshad, 1954b; Tan, 1995). The leached cations were quantitatively determined by inductively coupled plasma mass spectroscopy (ICP-MS).

Thermogravimetric (TG) was performed using the dynamic method on a Mettler Toledo A851 TGA/SDTA instrument. For TG analysis, about 15 mg powder was placed in an open $150 \mu \mathrm{L}$ alumina pan. Temperature was scanned from 25 to $1000{ }^{\circ} \mathrm{C}$ at a rate of $10{ }^{\circ} \mathrm{C} / \mathrm{min}$ with air flowing at a rate of $50 \mathrm{~mL} / \mathrm{min}$. 
Thermal expansion measurements were conducted on a TA instruments Q400 Thermo Mechanical Analyzer. The thickness of the Micron grade flakes tested ranged from $91 \mu \mathrm{m}$ to $231 \mu \mathrm{m}$ and their cross-sectional surface area varied from ca. $1.66 \mathrm{~mm}^{2}$ to about $4.2 \mathrm{~mm}^{2}$. In each experiment, a single flake was sandwiched between the flat surface probe and the bottom surface of an alumina pan. The flake expansion behavior was measured under a suitably chosen applied force. In the dynamic scan experiments the temperature was scanned from 30 ${ }^{\circ} \mathrm{C}$ to $1000{ }^{\circ} \mathrm{C}$ in argon at a scan rate of $10^{\circ} \mathrm{C} / \mathrm{min}$. Since the objective was to follow free expansion of the flakes, the lowest possible force $(0.001 \mathrm{~N})$ was applied. The expansion relative to the original flake dimension is reported.

Additional TMA experiments were limited to the sodium "vermiculite” obtained after six month of brine exposure. The effect of the magnitude of the applied force was investigated using settings of $0.05,0.20$ and $1.0 \mathrm{~N}$. Finally, the expansion behavior of flakes, subjected to a stepwise increasing temperature change protocol, was investigated. In these experiments the temperature was scanned at $10{ }^{\circ} \mathrm{C} / \mathrm{min}$ to an isothermal hold temperature where the sample was kept for 10 minutes before the temperature scan was continued. The first hold temperature was $270{ }^{\circ} \mathrm{C}$ and the subsequent hold temperatures were set at $10{ }^{\circ} \mathrm{C}$ increments with the final isothermal halt at $340{ }^{\circ} \mathrm{C}$.

For X-ray Diffraction analysis (XRD), samples of neat and exchanged “vermiculite” were split and a sub-sample of each was homogenized and milled to a fine powder. The evaluation was done on random and oriented preparations. The neat "vermiculite” was saturated with $\mathrm{Mg}$ prior to the various treatments. All oriented preparations were analyzed in an air-dried state (AD), after Ethylene Glycol solvation (EG) and heat treatment at $550^{\circ} \mathrm{C}$. X-Ray Diffraction data was obtained on a BRUKER D8 Advance diffractometer with $\mathrm{Cu}_{\mathrm{K} \alpha}$ radiation ( $\lambda=1.54060$ ), Johansson crystal primary monochromator and LynxEye detector with active area of $3.7^{\circ}$. Scans from 2 to $70^{\circ} 2 \theta$ for random powder preparations and 2 to $28^{\circ} 2 \theta$ for 
oriented slides were recorded in step scan modẹ at a speed of $0.01^{\circ} 2 \theta$ steps size/4 s and generator settings of $40 \mathrm{kV}$ and $40 \mathrm{~mA}$. Mineral identification was based on BRUKER DIFFRAC $^{\text {Plus }}$ - EVA evaluation program using International Centre for Diffraction Data (ICDD) Inorganic/Organic Data base. Phase concentrations were determined by Rietveld quantitative method with DIFFRAC ${ }^{\text {Plus }}$ - TOPAS software and estimated accuracy of $\pm 1 \%$. Refinement of diffraction data was done using the same program.

Images of neat and Na-exchanged vermiculite were obtained on a JSM-840 scanning electron microscope equipped with Orion 6.60.4 software. For these studies the "vermiculite" flakes were mounted on adhesive carbon tape. The temperature driven dynamic exfoliation process was also studied under a scanning electron microscope (FEI QUANTA 200 ESEM) fitted with a heating stage. The samples were placed inside a crucible and mounted in the heating stage. They were viewed at 200x magnification. The pressure was $0.5 \mathrm{kPa}$, voltage $20 \mathrm{kV}$, spot size 6-7 and a working distance of $16-20 \mathrm{~mm}$. Temperature was ramped at $20{ }^{\circ} \mathrm{C} / \mathrm{min}$.

Fourier-Transform Infrared Spectroscopy (FT-IR) spectra were recorded using a Perkin Elmer Spectrum RX FT-IR, coupled with a computer using Spectrum v5.0.1 software, with a scan resolution of $2.0 \mathrm{~cm}^{-1}$. A total of 32 interferograms were collected for each sample applying single beam radiation. $\mathrm{KBr}$ compressed pellets were prepared from a fine powder that was obtained by grinding a mixture $3-5 \mathrm{mg}$ of sample with $100 \mathrm{mg}$ of dehydrated $\mathrm{KBr}$ using a mortar and pestle.

\section{RESULTS AND DISCUSSION}

Generally vermiculite features a flake-like morphology with striations, humps and folds as characteristic features on the surface. The brine treatment did not affect the macroscopic appearance of the Palabora material. Figure 1 shows a SEM picture of flakes that were 
exposed to brine for six months. The damage caused by the milling process is manifested by the folded and lacerated edge. Figure 2 shows the particle size distribution for the Micron grade. The particle size distribution shows an apparent bimodal distribution and was not materially affected by exposure to the concentrated brine. The lower peak ranges from ca. 5 $\mu \mathrm{m}$ to just above $200 \mu \mathrm{m}$. Since the material consists essentially of high aspect ratio flakes, the lower hump is indicative of the variation in flake thickness.

According to the Figure 3 the FT-IR spectra of the Na-exchanged form (6 months brine exposure) is almost identical to that of the neat vermiculite. All the IR spectra show a strong band at 3420-3446 $\mathrm{cm}^{-1}$ ascribed to the characteristic $\mathrm{O}-\mathrm{H}$ stretching vibration from $\mathrm{H}_{2} \mathrm{O}$ of hydration and bonded silanol groups. The position of this peak maximum depends on the nature of the interlayer cation present. Other strong bands are observed at around 1641-1646 $\mathrm{cm}^{-1}$. They are due to O-H bending vibrations in the water of hydration. At 995-999 $\mathrm{cm}^{-1}$ there is a strong band attributed to $\mathrm{Si}-\mathrm{O}-\mathrm{Si}$ and $\mathrm{Si}-\mathrm{O}-\mathrm{Al}$ stretching vibrations. The doublet bands at ca. $2355 \mathrm{~cm}^{-1}$ reveals the presence of chemisorbed $\mathrm{CO}_{2}$. It would appear that the sodium "vermiculite" has a higher proclivity for adsorbing $\mathrm{CO}_{2}$ from the atmosphere than the neat "vermiculite". These are surprising observations that are in conflict with the findings of Thomas and Bohor (1969). They reported a low affinity of vermiculite for $\mathrm{CO}_{2}$.

The XRF derived chemical compositions are presented in Table 1. The sodium content shows a step change from effectively zero (0.01 wt \%) to an average value of ca. $1.67 \pm 0.11$ wt \% after one month exposure and beyond. The presence of calcium and phosphorus is attributed to apatite and dolomite contamination. The unknown quantities in Scheme I were determined by fitting the formulae to the XRF data for the other elements using atom balances. In this calculation it was assumed that titanium and manganese formed part of the tetrahedral and octahedral sheets respectively. However, neglecting the existence of these impurities made little difference to the calculations. The composition estimated from the XRF 
data suggests about $60 \%$ biotite and $40 \%$ vermiculite with a CEC value equivalent to about $0.98 \mathrm{meq} / \mathrm{g}$.

According to the ICP results shown in Figure 4, the vermiculite interlayer regions initially contain both $\mathrm{Mg}^{2+}$ and $\mathrm{Ca}^{2+}$ as extractable cations in addition to some $\mathrm{K}^{+}$. The extraction data indicate almost quantitative replacement of the exchangeable $\mathrm{Mg}^{2+}$ and $\mathrm{Ca}^{2+}$ cations in the vermiculite phase, by $\mathrm{Na}^{+}$. The $\mathrm{Ca}^{2+}$ ions that are not replaced by $\mathrm{Na}^{+}$ions but exchangeable by $\mathrm{NH}_{4} \mathrm{OOCCH}_{3}$, are attributed to the presence of the apatite impurity $\left[\mathrm{Ca}_{3}\left(\mathrm{PO}_{4}\right)_{2}\right]$. The majority of the $\mathrm{K}^{+}$ions, i.e. those associated with the mica phase, are not available for exchange by sodium. This is consistent with previous findings (MacEwan et al. 1961, Newman, 1987).

The main mineral impurities found via XRD analysis were dolomite and apatite. Figure 5 depicts the evolution of the XRD spectra with time of brine treatment. The neat material features a strong broad peak at $2 \theta=7.43^{\circ}(1.19 \mathrm{~nm})$ and weaker reflections at $2 \theta=6.17^{\circ}$ $(1.43 \mathrm{~nm})$ and $2 \theta=8.77^{\circ}(1.02 \mathrm{~nm})$. The $1.43 \mathrm{~nm}$ reflection is consistent with a vermiculite phase with two (slightly incomplete) water layers in the galleries forming hydration shells around the exchangeable cations (Mathieson, 1958). The $1.02 \mathrm{~nm}$ reflection is from the mica (biotite/phlogopite). Perfectly alternating 50/50 mixed layered vermiculite, i.e. "hydrobiotite”, features reflections at $2.441 \mathrm{~nm}(001)$ and $1.221 \mathrm{~nm}$ (002) (Newman, 1987; Ruiz-Amil et al., 1992). In the present sample the main peak is located at higher $2 \theta$ angles. This and the extensive line broadening are indicative of a random distribution of the vermiculite layers.

While the sodium uptake reaches a plateau by the first month, the XRD spectra shown in Figure 5 suggest continued evolution up to month six. The intensity of the main reflection increases with time but settles at its ultimate d-spacing of $1.12 \mathrm{~nm}$ already by the end of the first month. After six months of brine exposure reflections are found at circa $2.44 \mathrm{~nm}, 1.22$ $\mathrm{nm} ; 1.12 \mathrm{~nm}$ and $1.01 \mathrm{~nm}$. The broad reflection at ca. $2.44 \mathrm{~nm}$ and the well-resolved $1.21 \mathrm{~nm}$ 
reflections are diagnostic for the formation of a more ordered structure similar to "hydrobiotite". However, pattern simulations using NEWMOD indicate that its composition is ca. $45 \%$ vermiculite.

The thermogravimetric (TG) curves for unaltered materials and the Na-exchanged forms are shown in Figure 6. Mass loss commences below $100{ }^{\circ} \mathrm{C}$ and occurs in several steps for all the samples. As shown in Figure 8 the total mass loss was $7-9 \mathrm{wt} \%$ for all samples. This compares with a total expected mass loss of $10.5 \mathrm{wt} \%$, with interlayer water contributing 6.5 wt \%, for the structure indicated in Scheme II with the assumption that $n=4$.

$$
\begin{aligned}
& 0.60\left(\mathrm{Mg}_{2.60} \mathrm{Fe}_{0.60}^{2+}\right)\left[\mathrm{Si}_{3.2} \mathrm{Al}_{0.78} \mathrm{Fe}_{0.02}^{3+}\right] \mathrm{O}_{10}(\mathrm{OH})_{2} \mathrm{~K}_{0.49}^{+} \\
& +0.40\left(\mathrm{Mg}_{2.60} \mathrm{Fe}_{0.60}^{2+}\right)\left[\mathrm{Si}_{3.2} \mathrm{Al}_{0.78} \mathrm{Fe}_{0.02}^{3+}\right] \mathrm{O}_{10}(\mathrm{OH})_{2} \mathrm{Mg}_{0.20}^{2+} . n \mathrm{H}_{2} \mathrm{O}
\end{aligned}
$$

Scheme II: Structural formula consistent with the XRF data

Figure 7 reports overall mass loss and percentages for the temperature regions $<250{ }^{\circ} \mathrm{C}$; $250-520{ }^{\circ} \mathrm{C}$, and $520-1200{ }^{\circ} \mathrm{C}$. Most of the mass loss occurs in the first and final temperature ranges. As shown below, most of the vermiculite exfoliation occurs in the temperature range $250-520^{\circ} \mathrm{C}$. Surprisingly, the explosive exfoliation corresponds to the release of less than $0.5 \mathrm{wt} \%$ water!

Free expansion curves, obtained at a very low TMA load and with constant temperature ramping, are shown in Figure 8. These curves feature a rather abrupt rise at the onset temperature followed by a more gradual expansion over a temperature range of several hundred degrees Celsius. The initial steep section leads to linear expansions equivalent to three to six times the initial flake thickness at rates ranging from $3 \% / \mathrm{s}$ to $16 \% / \mathrm{s}$. The 
maximum in expansion is attained at a temperature around $700{ }^{\circ} \mathrm{C}$. Above this temperature some sample contraction is observed.

The exfoliation onset temperature, of the neat material, exceeds $420^{\circ} \mathrm{C}$. All the sodium exchanged samples have similar exfoliation onset temperatures, in the range $260{ }^{\circ} \mathrm{C}$ to 300 ${ }^{\circ} \mathrm{C}$. This means that the simple device of exchanging the interlayer magnesium ions with sodium has lowered the exfoliation onset temperature to a range that may have technological significance for intumescent fire barrier applications.

Figure 9 shows the effect of the applied force on expansion behavior of the six month exchanged sodium vermiculite. The observed variation in the initial stages of expansion is attributed to the variability of the properties of individual flakes rather than the change in the applied force. The smallest flake tested had a cross-sectional area of $1.66 \mathrm{~mm}^{2}$. At an applied force of $1 \mathrm{~N}$ this corresponds to a pressure of merely 0.6 MPa. The lowest onset temperature exceeds $250{ }^{\circ} \mathrm{C}$ and at this point the vapor pressure of water is already 3.92 MPa. So it is unlikely that the TMA applied force would have affected the expansion onset temperature.

Figure 10 shows the results for the stepped-temperature-increase protocol on the expansion behavior of six-month sodium "vermiculite". It again reveals considerable variability in the behavior of the individual flakes. Notably, significant expansion occurs during the isothermal periods. This is indicated by the stair-case like expansion as a function of temperature. Figure 10 shows that the expansion of Flake A commenced at the first isothermal hold temperature of $270^{\circ} \mathrm{C}$. The temporal evolution of this isothermal expansion is shown in Figure 11 together with isothermal expansion results for other flakes proceeding at different hold temperatures. Remarkably, in at least two of these curves, the expansion is characterized by an induction time before a sigmoidal expansion occurs. It is assumed that water is continuously lost as time proceeds during the isothermal period. The observed time delay then suggests that expansion 
is triggered when a critical water content level is reached inside the galleries. The expansion of Flake A, at the hold temperature of $270{ }^{\circ} \mathrm{C}$, actually takes place in two distinct steps. This can be explained by assuming that the composition of the flakes is not homogeneous along the c-axis, i.e. that the vermiculite content varies with distance along the flake thickness.

The expansion process of sodium-exchanged vermiculite was studied as a function of time and temperature in an ESEM. Selected micrographs are shown in Figure 12. Careful study of the full video clearly shows heterogeneous exfoliation of a single flake. The expansion occurs in stages at different positions along the flake thickness dimension. Remarkable is the fact that significant expansion still occurs despite the low pressure of only $0.5 \mathrm{kPa}$ in the ESEM cavity. Marcos et al. (2003) have found that exposing the vermiculite to vacuum causes rapid dehydration. However, below $120^{\circ} \mathrm{C}$, the vacuum dehydration is arrested at a one-water layer state. These observations support the notion that exfoliation is not dependent on the presence of water above this level.

\section{CONCLUSIONS}

The effect of sodium ion exchange on the properties of Palabora "vermiculite" was studied using scanning electron microscopy (SEM), X-ray fluorescence spectroscopy (XRF), inductively coupled plasma mass spectroscopy (ICP-MS), X-ray diffraction (XRD) and thermo-mechanical analysis (TMA). The ion exchange was done by submerging the macroscopic flakes in saturated brine for periods of several months. The sodium content reached a plateau value by month one but the XRD pattern continued to change, reaching a final form only after a six month exposure. The final XRD pattern indicates the presence of at least two distinct interstratified phases containing different amounts of vermiculite proper. The thermal expansion of the neat vermiculite commenced at temperatures above $420{ }^{\circ} \mathrm{C}$ and 
reached levels exceeding an eight-fold expansion at ca. $700{ }^{\circ} \mathrm{C}$. Beyond this temperature a slight contraction occurred. Sodium exchange lowered the exfoliation onset temperature to below $300{ }^{\circ} \mathrm{C}$.

\section{ACKNOWLEDGEMENTS}

Financial support for this research from the Institutional Research Development Programme (IRDP) and the South Africa/Mozambique Collaboration Programme of the National Research Foundation (NRF) is gratefully acknowledged.

\section{REFERENCES}

Barshad, I., 1954a. Cation exchange in micaceous minerals: 1. Replaceability of the interlayer cations of vermiculite with ammonium and potassium ions. Soil Sci. 77, 463-472.

Barshad, I., 1954b. Cation exchange in micaceous minerals: 11. Replaceability of ammonium and potassium from vermiculite, biotite and montmorillonite. Soil Sci. 78, 57-76.

Basset, W. A., 1963. The geology of vermiculite occurrences. Clays and Clay Minerals $10^{\text {th }}$ Conference, Pergamon Press, New York, 61-96.

Baumeister, W., Hahn, M., 1976. An improved method for preparing single crystal specimen supports: $\mathrm{H}_{2} \mathrm{O}_{2}$ exfoliation of vermiculite. Micron 7, 247-251. 
Bergaya, F., Theng, B. K. G., Lagaly, G. (Editors) 2006. Handbook of Clay Science. Developments in Clay Science Series, Volume 1, Amsterdam: Elsevier.

Brindley, G. W., Brown, G. 1980. Crystal Structure of clay minerals and their X-ray identification; 3rd ed. Mineralogical Society Monograph No 5. Mineralogical Society, London.

Brindley, G. W., Zalba, P. E., Bethke, C. M., 1983. Hydrobiotite, a regular 1:1 interstratification of biotite and vermiculite layers. Am. Mineral. 68, 420-425.

Boss, B. D., 1967. Differential thermal analysis of biotitic vermiculite to determine vermiculite content. Am. Mineral. 52, 294-298.

da Fonseca, M. G., de Oliveira, M. M., Arakaki, L. N. H., Espinola, J. G. P., Airoldi, C. A., 2005. Natural vermiculite as an exchanger support for heavy cations in aqueous solution. J. Colloid Interface Sci. 285, 50-55.

da Silva Jr., U. G., Melo, M. A. F., da Silva, A. F., de Farias, R. F., 2003. Adsorption of crude oil on anhydrous and hydrophobized vermiculite. J. Colloid Interface Sci. 260, 302-304.

de Haro, M. C. J., Pérez-Rodríguez, J. L., Poyato, J., Pérez-Maqueda, L. A., RamírezValle, V., Justo, A., Lerf, A., Wagner, F. E., 2005. Effect of ultrasound on preparation of porous materials from vermiculite. Appl. Clay Sci. 30, 11-20.

Frank, D., Edmond, L., 2001. Feasibility for identifying mineralogical and geochemical tracers for vermiculite ore deposits. United States Environmental Protection Agency, Seattle.

Friedman, S. D., McKinney, R. W., Ou, C., Spotnitz, R. M., Wu, S., 1994. Vermiculite composition with improved thermal expansion properties. US Patent 5340558. 
Harben, P. W., Roberts, R. L., 1990. Industrial Minerals Geology and World Deposits. Metal Bulletin Plc, London.

Herbert, H. J., Moog, H. C., 1999. Cation exchange, interlayer spacing and water content of MX-80 bentonite in high molar saline solutions. Eng. Geol. 54, 55-65.

Herbert, H. J., Kasbohm, J., Moog, H. C., Henning, K. H., 2004. Long-term behaviour of the Wyoming bentonite MX-80 in high saline solutions. Appl. Clay Sci. 26, 275-291.

Hudson, E. A., Terminello, L. J., Viani, B. E., Denecke, M., Reich, T., Allen, P., Bucher, J. J., Shuh, D. K., Edelstein, N. M., 1999. The structure of $\mathrm{U}^{6+}$ sorption complexes on vermiculite and hydrobiotite. Clays Clay Miner. 47, 439-457.

Justo, A., 1989. Expansibility of some vermiculites. Appl. Clay Sci. 4, 509-519.

Justo, A., Pérez-Rodríguez, J. L., Sánchez-Soto, P. J., 1993. Thermal studies of vermiculites and mica-vermiculite interstratifications. J. Thermal Anal. 40, 59-65.

Langer, R. L., Marlor, A. J., 1981. Intumescent sheet material. US Patent 4305992.

Lopez-Gonzalez, J. D. D., J. Cano-Ruiz, 1957. Surface area changes of a vermiculite by acid and thermal treatment. Clays Clay Miner. 6, 399-405.

MacEwan, D. M. C., Ruiz-Amil, A., Brown, G., 1961. Interstratified clay minerals. In: Brown, G. (Editor), The X-ray identification and crystal structures of clay minerals, Mineralogical Society, London, 393-445,

Marcos, C., Arango, Y. C., Rodriguez, I., 2009. X-ray diffraction studies of the thermal behaviour of commercial vermiculites. Appl. Clay Sci. 42, 368-378.

Marcos, C., Argüelles, A., Ruiz-Conde, A., Sánchez-Soto, P.J., Blanco, J.A., 2003. Study of the dehydration process of vermiculites by applying a vacuum pressure: Formation of interstratified phases. Mineral. Mag. 67, 1253-1268. 
Mathieson, A. M., 1958. Mg-vermiculite: A refinement of the crystal structure of the 14.36 Å phase. Amer. Mineral. 43, 216-227.

Newman, A. C. D., Brown, G., 1987. The chemical constitution of clays. In: Newman, A. C. D. (Editor), Chemistry of Clays and Clay Minerals. Longman Scientific \& Technical Mineralogical Society, London, 1-128.

Obut, A., Girgin, I., 2002. Hydrogen peroxide exfoliation of vermiculite and phlogopite. Miner. Eng. 15, 683-687.

Ou, C., Bablouzian, L., 1994. Intumescent sheet material. US Patent 5340643.

Pérez-Maqueda, L. A., Balek, V., Poyato, J., Pérez-Rodriquez, J. L., Šubrt, J., Bountsewa, I. M., Beckman, I. N., Málek, Z., 2003. Study of natural and ion exchanged vermiculite by emanation thermal analysis, TG, DTA and XRD. J. Thermal Anal. Cal. 71, 715-726.

Raman, K. V. V., Jackson, M. L., 1963. Vermiculite surface morphology. Twelfth National Conference on Clays and Clay Minerals 2, 423-429.

Ruiz-Amil, A., de la Cruz, F. A., Ruiz-Conde, A., 1992. Study of a material from Libby, Montana, containing vermiculite and hydrobiotite: intercalation with aliphatic amines. Clay Miner. 27, 257-263.

Reynolds, R. C. Jr., 1985. NEWMOD ${ }^{\circledR}$. A Computer Program for the Calculation of OneDimensional Diffraction Patterns of Mixed-Layered Clays. R.C. Reynolds, Jr., 8 Brook Rd., Hanover, NH, USA.

Schoeman, J. J., 1989. Mica and vermiculite in South Africa. J. S. Afr. Inst. Min. Metall. 89, 1-12. 
Schwellnus, C. M., 1938. Vermiculite deposits in the Palabora area, N.E. Transvaal. Geological Survey, 7-28, South Africa.

Suzuki, S., Sazarashi, M., Akimoto, T., Haginuma, M., Suzuki, K., 2008. A study of the mineralogical alteration of bentonite in saline water. Appl. Clay Sci. 41, 190-198.

Tan, K. H., 1996. Soil sampling, preparation, and analysis, Marcel Dekker, New York, 114-126, 285-294, 308-330.

Thomas, J. Jr., Bohor, B. F., 1969. Surface area of vermiculite with nitrogen and carbon dioxide as adsorbates. Clays Clay Miner. 17, 205-209.

Tjong, S. C., 2006. Structural and mechanical properties of polymer nanocomposites. Mater. Sci. Eng. R 53, 73-197.

Tomanec, R., Popov, S., Vučinič, D., Lazič, P., 1997. Vermiculite from Kopaonik (Yugoslavia): characterization and processing. Fizykochemiczne Problemy Mineralurgii 31, 247-254.

van der Marel, H. W., Beutelspacher, H., 1976. Atlas of infrared spectroscopy of clay minerals and their admixtures, Elsevier, Amsterdam.

Wada, T., 1973a. Manufacture of expanded vermiculite employing a urea compound and low temperatures. US Patent 3753923.

Wada, T., 1973b. Method for the expansion of vermiculite. US Patent 3758415.

Walker, G. F., 1961. Vermiculite minerals. In: Brown, G. (Editor), The X-ray identification and crystal structures of clay minerals. Mineralogical Society, London, 297-342.

Zhu, R., Zhu, L., Zhu, J., Xu, L, 2008. Structure of cetyltrimethylammonium intercalated hydrobiotite, Appl. Clay Sci. 42, 224-231. 


\section{Table Captions}

Table 1: XRF composition analysis.

\section{Figure Captions}

Figure 1. SEM picture of "vermiculite” flakes treated for 6 months in saturated brine.

Figure 2. Particle size distribution for the Micron grade "vermiculite" in neat form and the product obtained after immersion in brine for a period of six months.

Figure 3. FTIR spectra for the Micron grade "vermiculite" in neat form and the product obtained after immersion in brine for a period of six months.

Figure 4. The effect of brine treatment time on the extractable interlayer composition.

Figure 5. Evolution of the XRD spectra as a function of brine exposure time

Figure 6. TG curves for Micron grade “vermiculite” treated for six months in brine.

Figure 7. TG Mass loss in selected temperature ranges for the Micron grade "vermiculite” treated for six months in brine. Most of the exfoliation occurs in the temperature range $250{ }^{\circ} \mathrm{C}$ to $520{ }^{\circ} \mathrm{C}$. This plot shows that the exfoliation is caused by less than $0.5 \mathrm{wt} \%$ water turning into steam. 
Figure 8. TMA expansion of Superfine grade "vermiculite” treated for six months in brine.

Figure 9. Effect of the TMA applied force on the expansion behavior of the Superfine grade "vermiculite" flakes treated for six months in brine.

Figure 10. Effect of intermittent temperature stepping (scan at $10{ }^{\circ} \mathrm{C} / \mathrm{min}$ to isothermal hold temperature, wait for $10 \mathrm{~min}$ and commence scan to next halt) on the expansion behavior of the flakes (Superfine vermiculite in its six month Na-exchanged form).

Figure 11. TMA characterization of isothermal expansion at selected temperatures (Superfine grade “vermiculite” flakes treated for six months in brine).

Figure 12. ESEM micrographs for the expansion of Superfine grade "vermiculite" treated for six months in brine. A. Just before exfoliation commences at $263^{\circ} \mathrm{C}$; B. and C. During exfoliation at $345^{\circ} \mathrm{C}$ at $367^{\circ} \mathrm{C}$ respectively; and D. After exfoliation at $432^{\circ} \mathrm{C}$. 


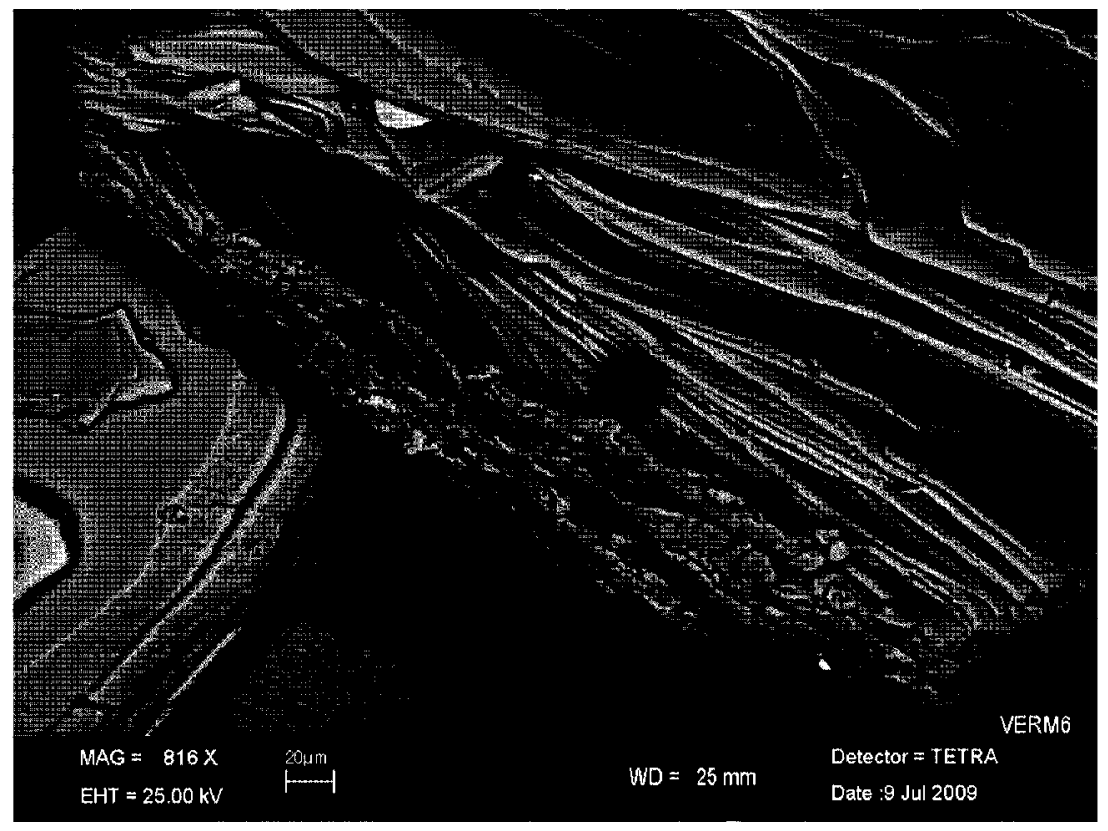

Figure 1. SEM picture of "vermiculite” flakes treated for 6 months in saturated brine. 


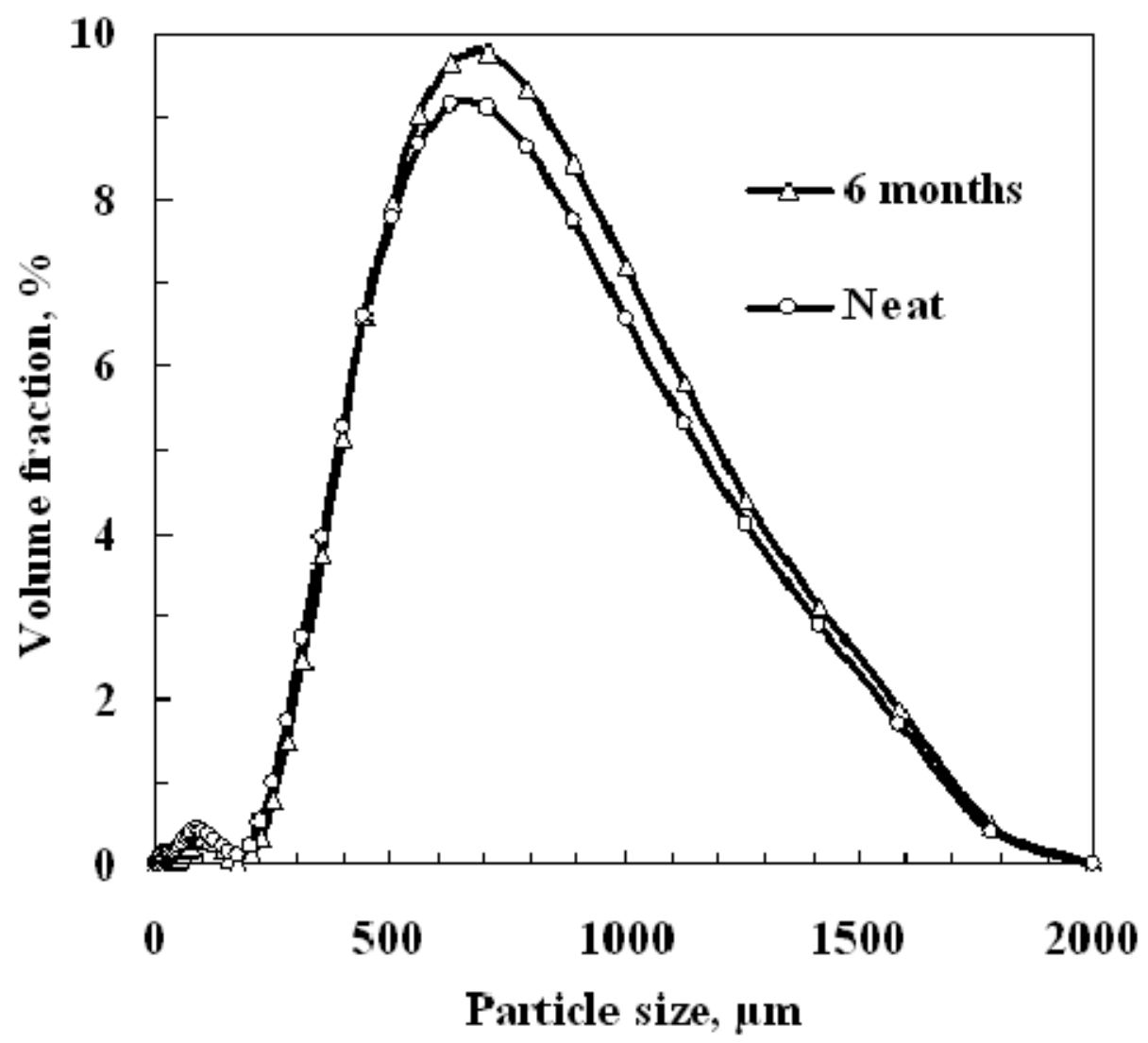

Figure 2. Particle size distribution for the Micron grade "vermiculite" in neat form and the product obtained after immersion in brine for a period of six months. 


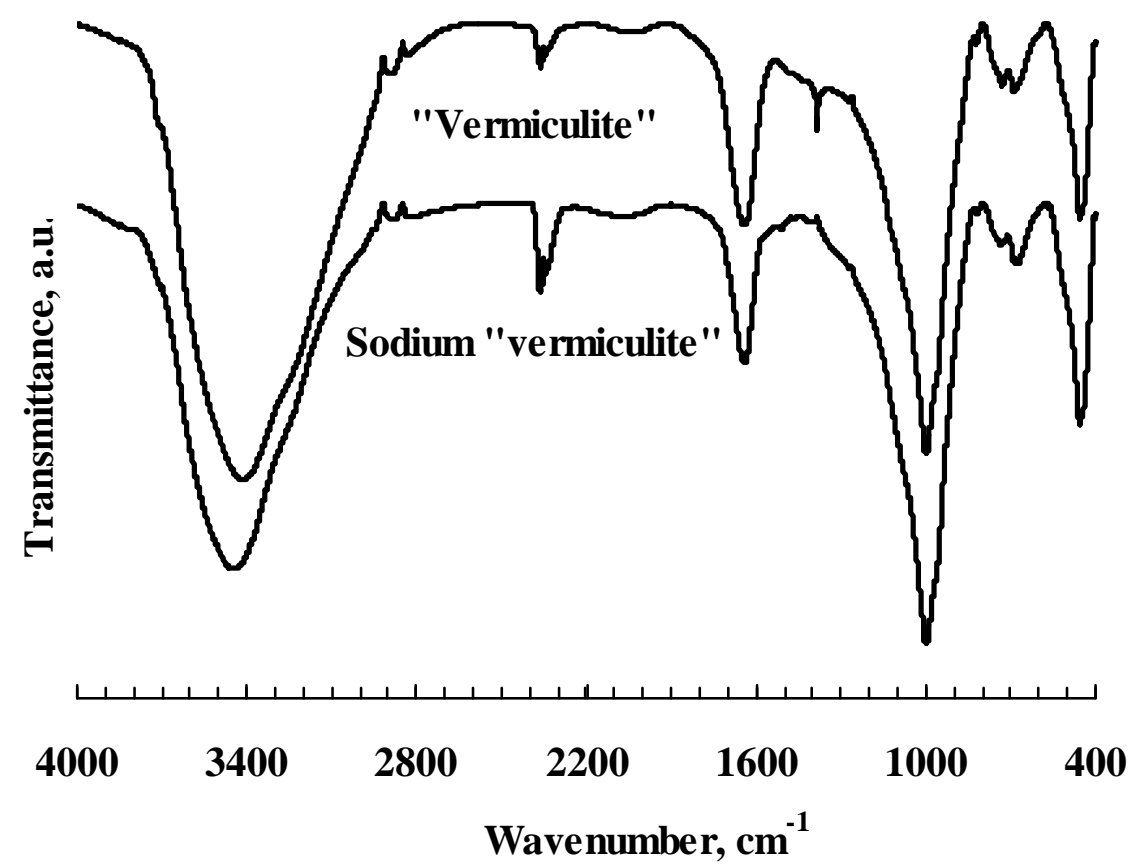

Figure 3. FTIR spectra for the Micron grade "vermiculite" in neat form and the product obtained after immersion in brine for a period of six months. 


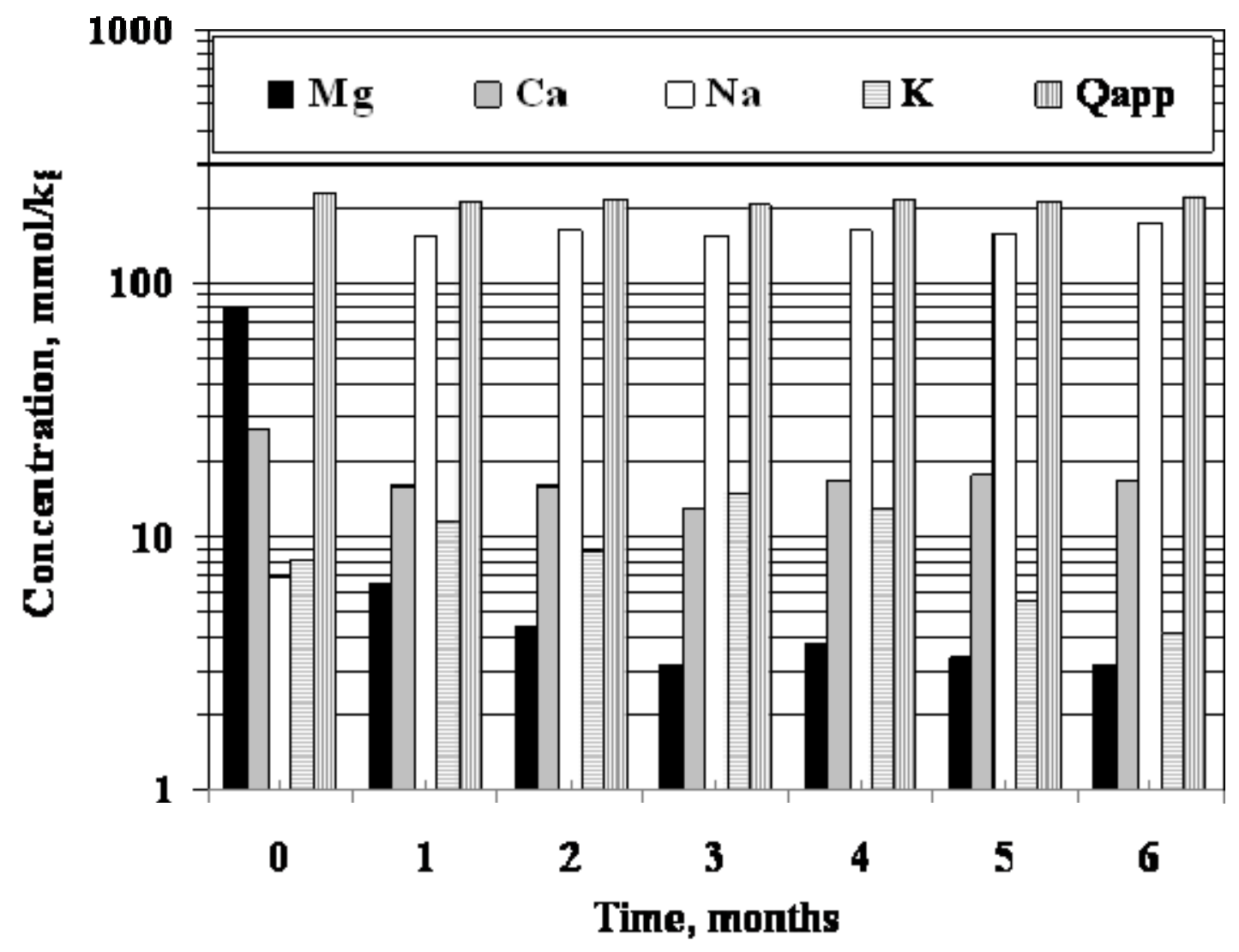

Figure 4. The effect of brine treatment time on the extractable interlayer composition. 


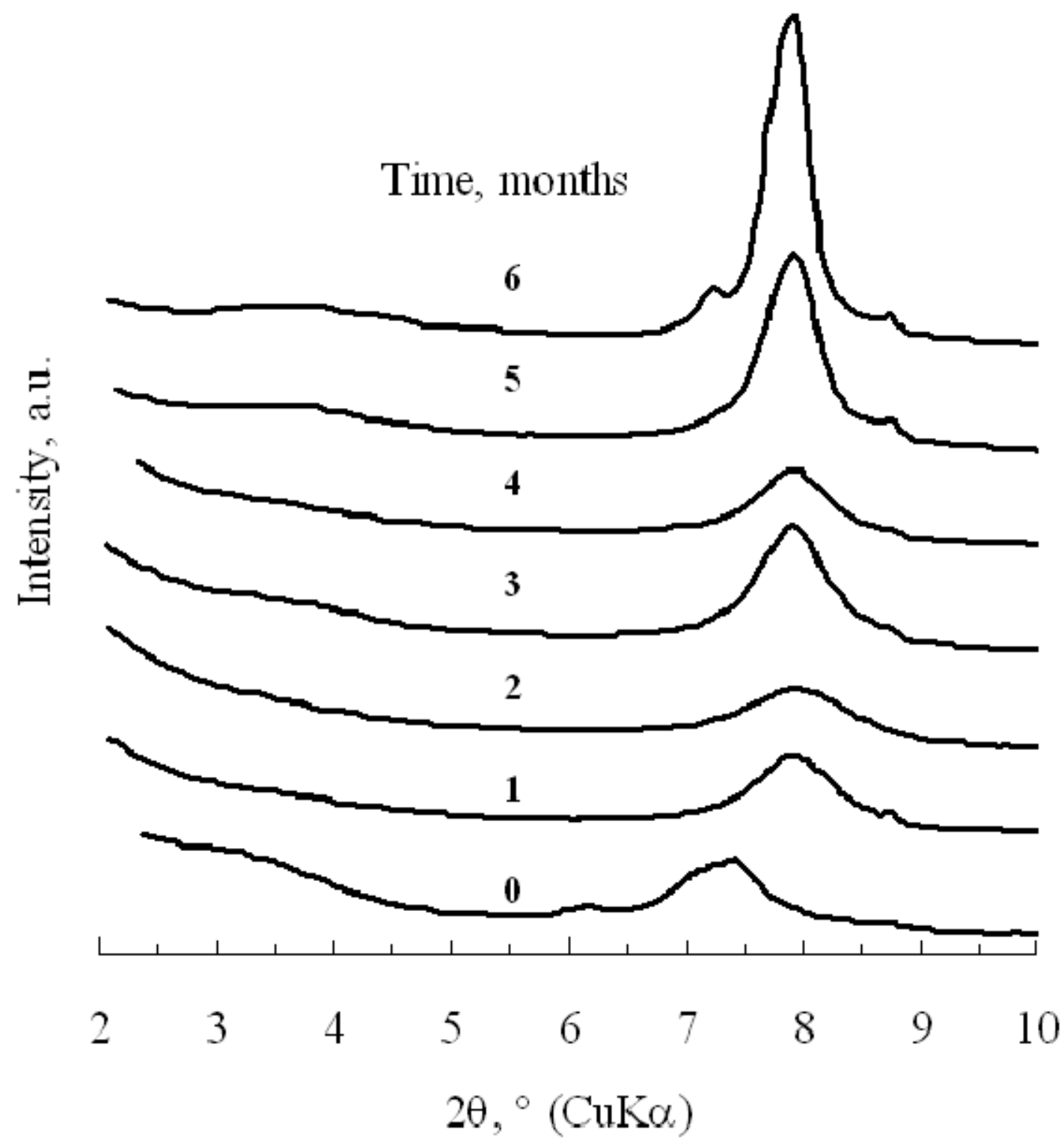

Figure 5. Evolution of the XRD spectra as a function of brine exposure time 


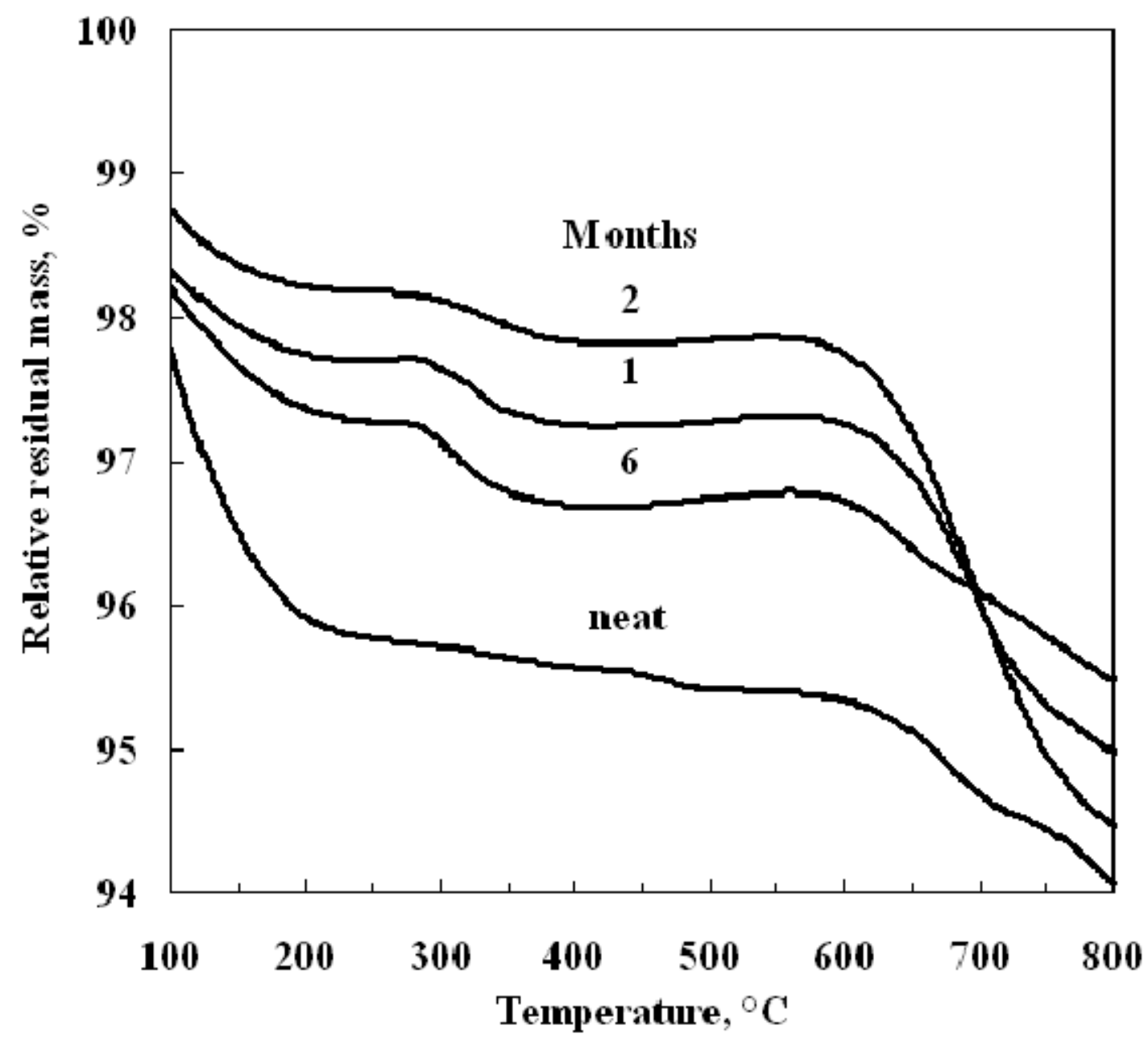

Figure 6. TG curves for Micron grade "vermiculite" treated for six months in brine. 


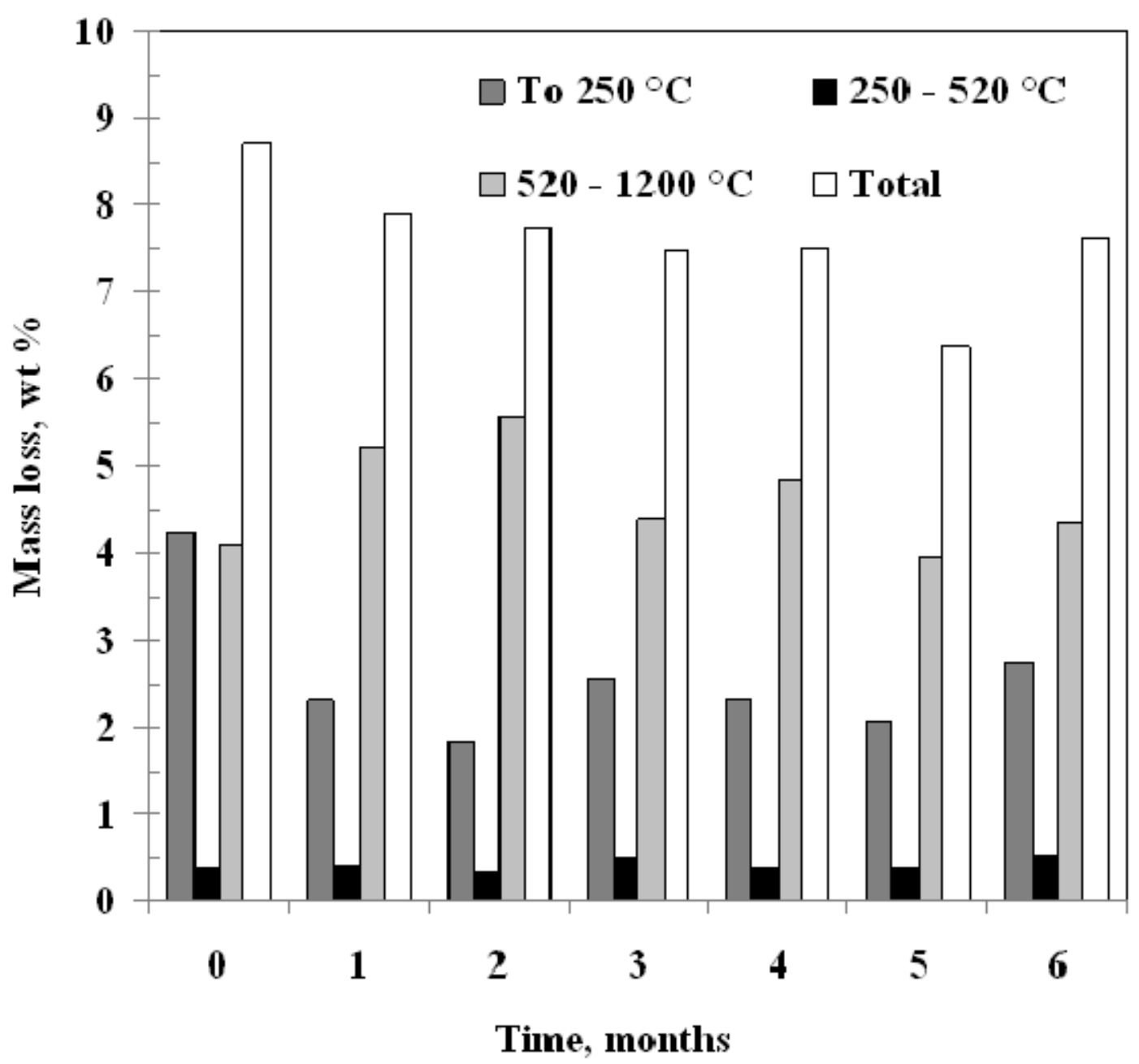

Figure 7. TG Mass loss in selected temperature ranges for the Micron grade "vermiculite" treated for six months in brine. Most of the exfoliation occurs in the temperature range $250{ }^{\circ} \mathrm{C}$ to $520^{\circ} \mathrm{C}$. This plot shows that the exfoliation is caused by less than 0.5 wt \% water turning into steam. 


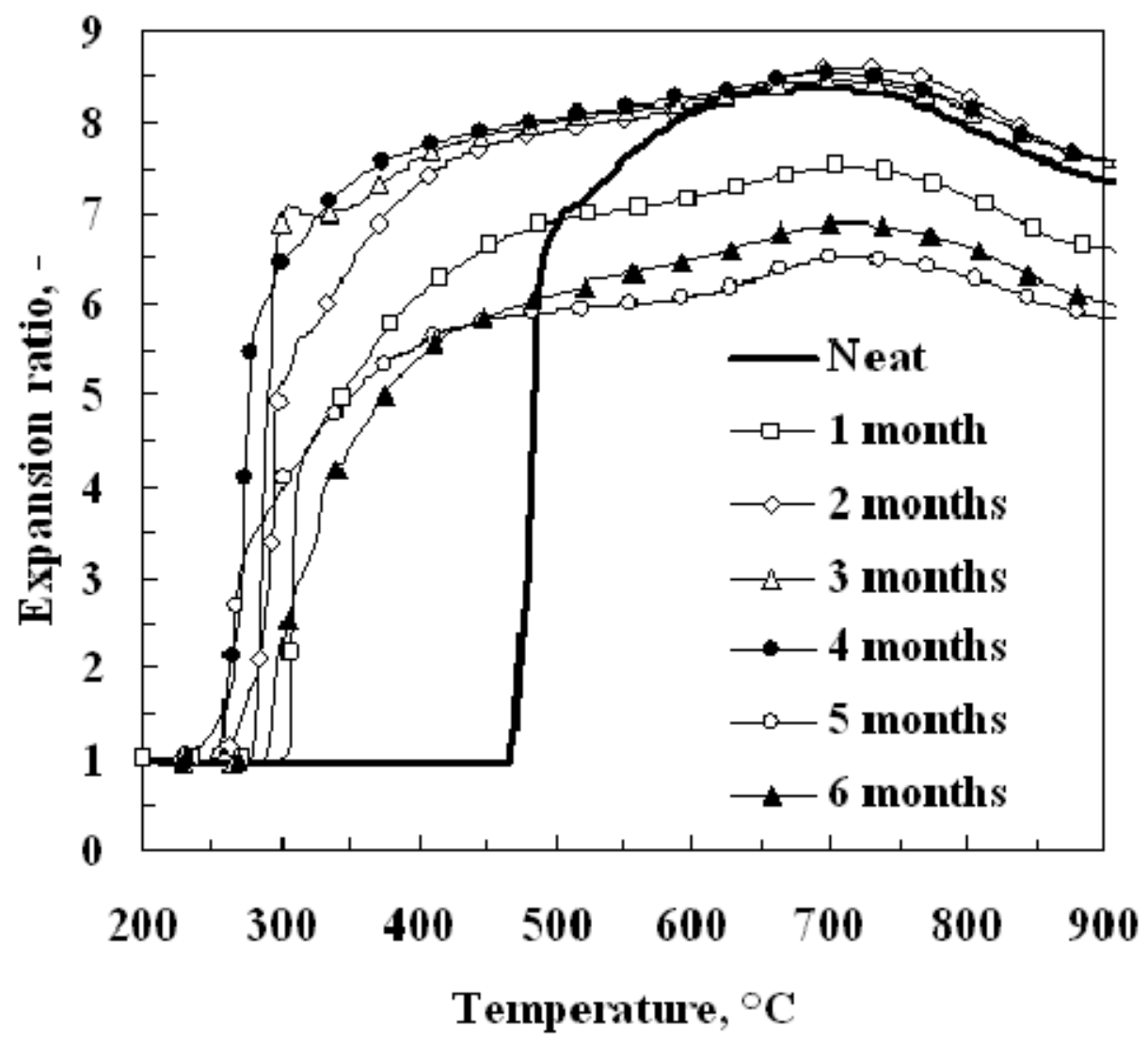

Figure 8. TMA expansion of Superfine grade "vermiculite" treated for six months in brine. 


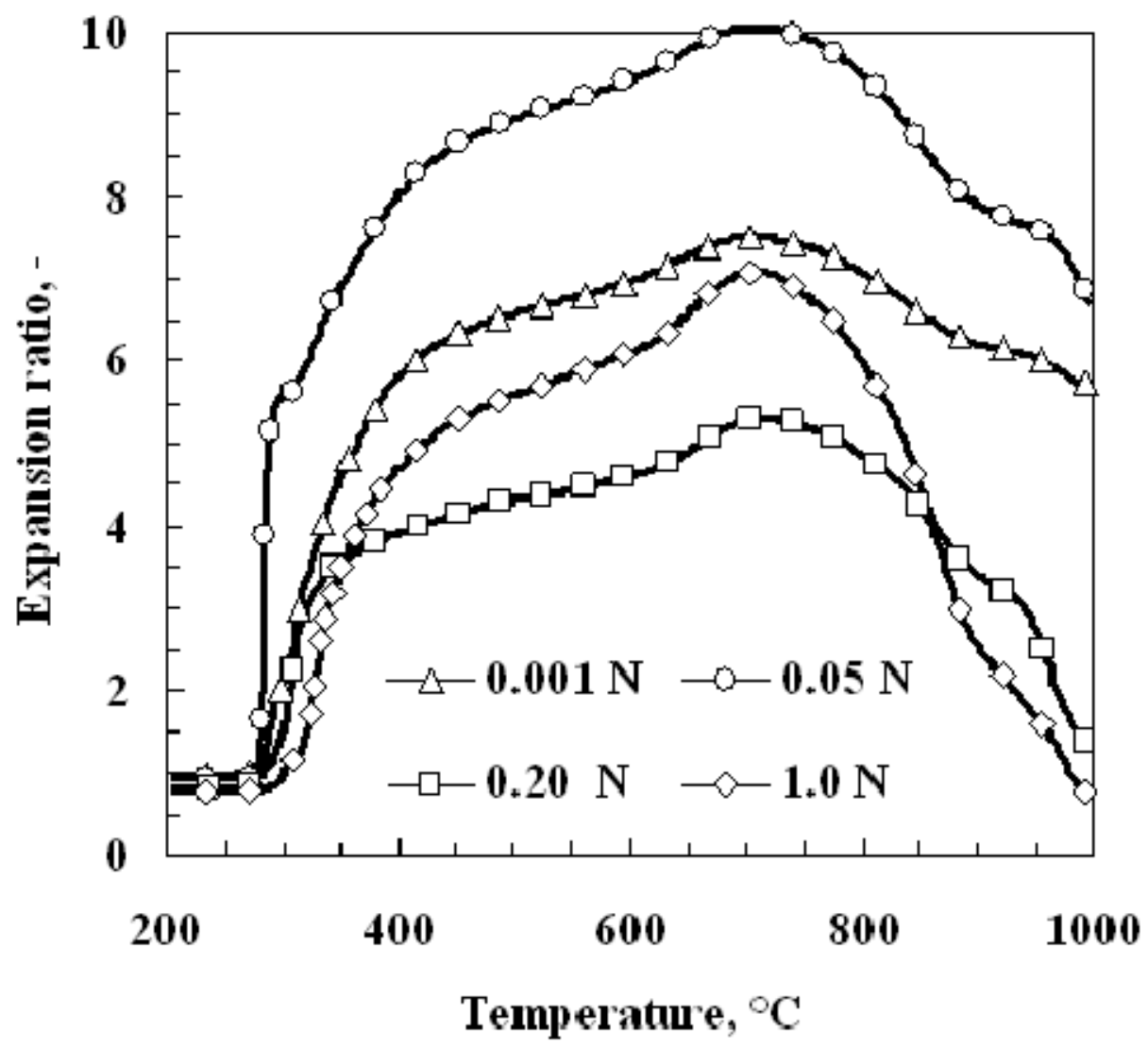

Figure 9. Effect of the TMA applied force on the expansion behavior of the Superfine grade "vermiculite" flakes treated for six months in brine. 


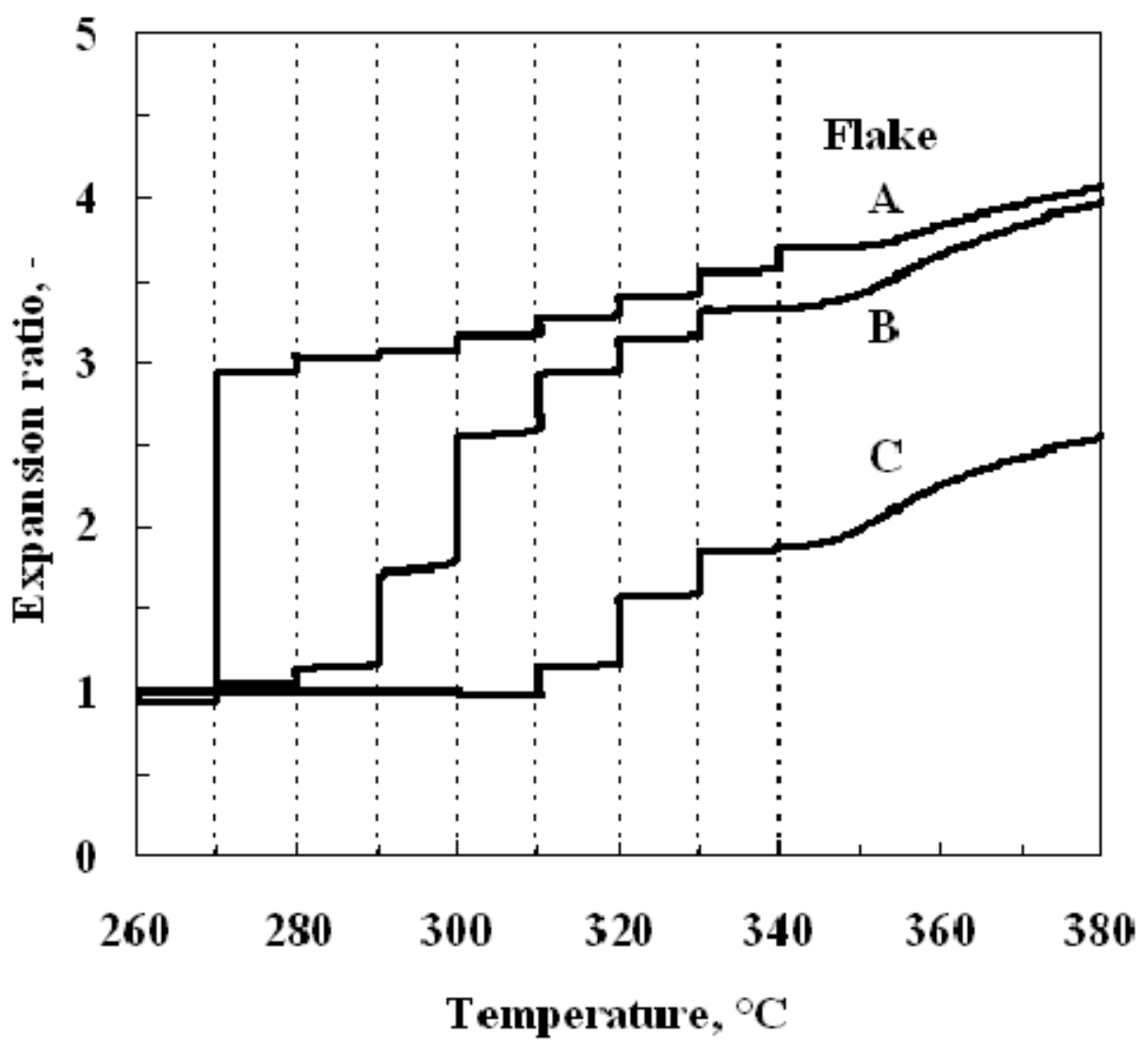

Figure 10. Effect of intermittent temperature stepping (scan at $10^{\circ} \mathrm{C} / \mathrm{min}$ to isothermal hold temperature, wait for $10 \mathrm{~min}$ and commence scan to next halt) on the expansion behavior of the flakes (Superfine vermiculite in its six month Na-exchanged form). 


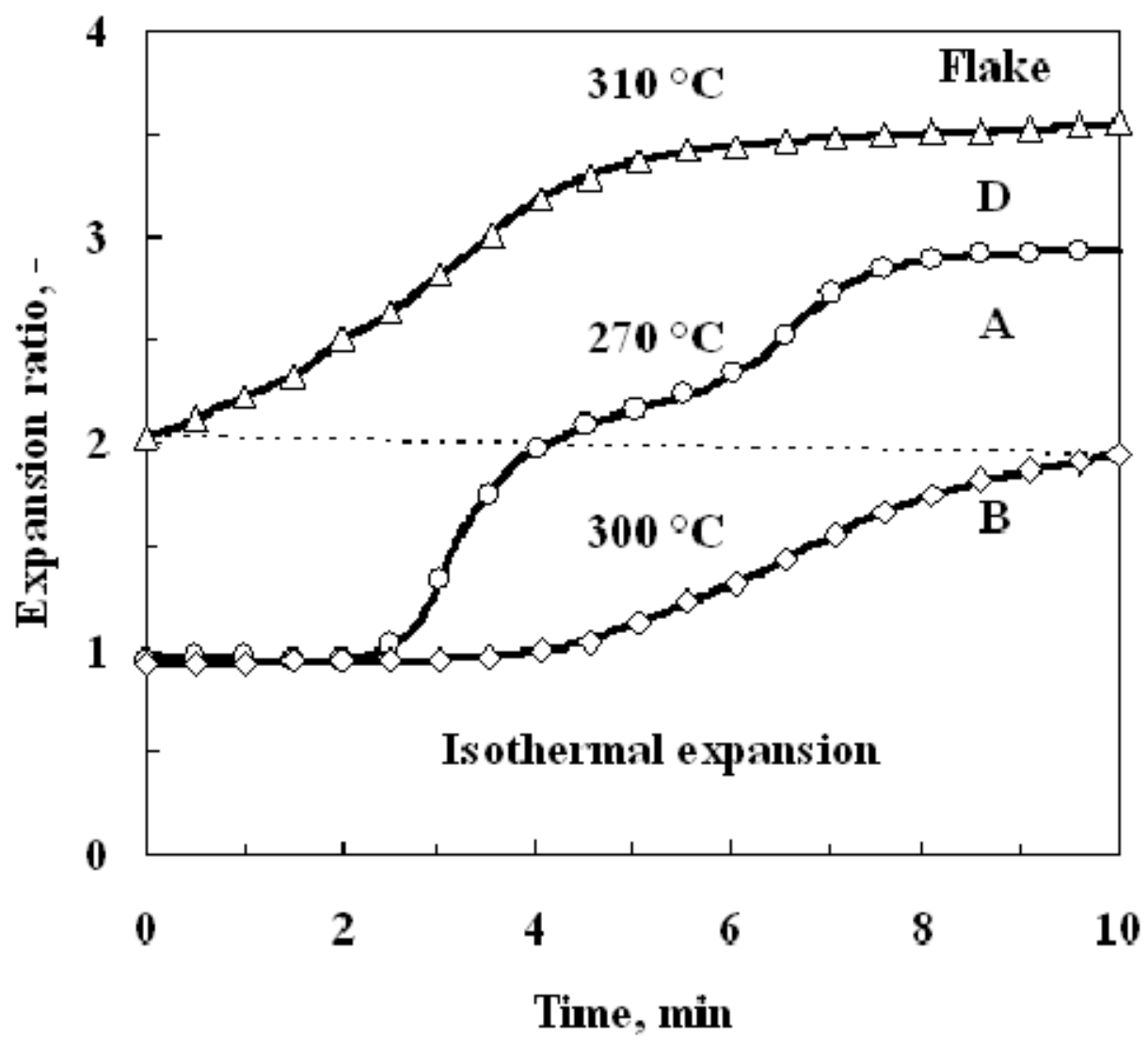

Figure 11. TMA characterization of isothermal expansion at selected temperatures (Superfine grade "vermiculite" flakes treated for six months in brine). 


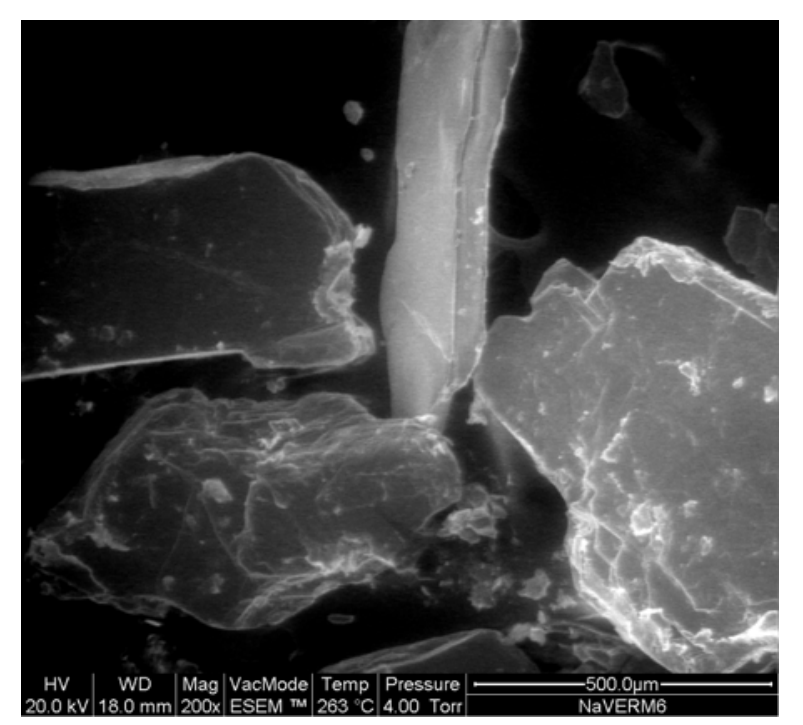

A

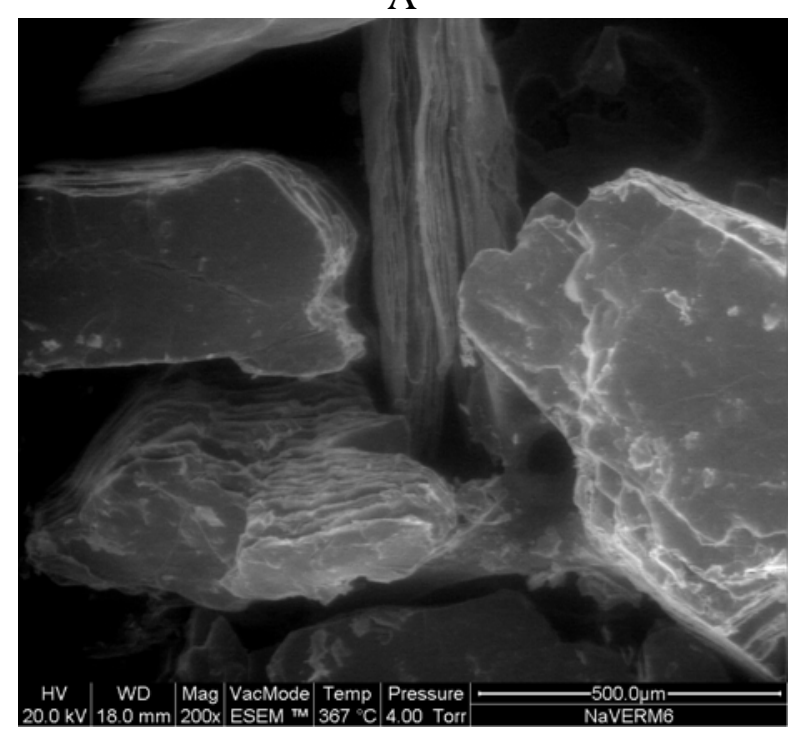

C

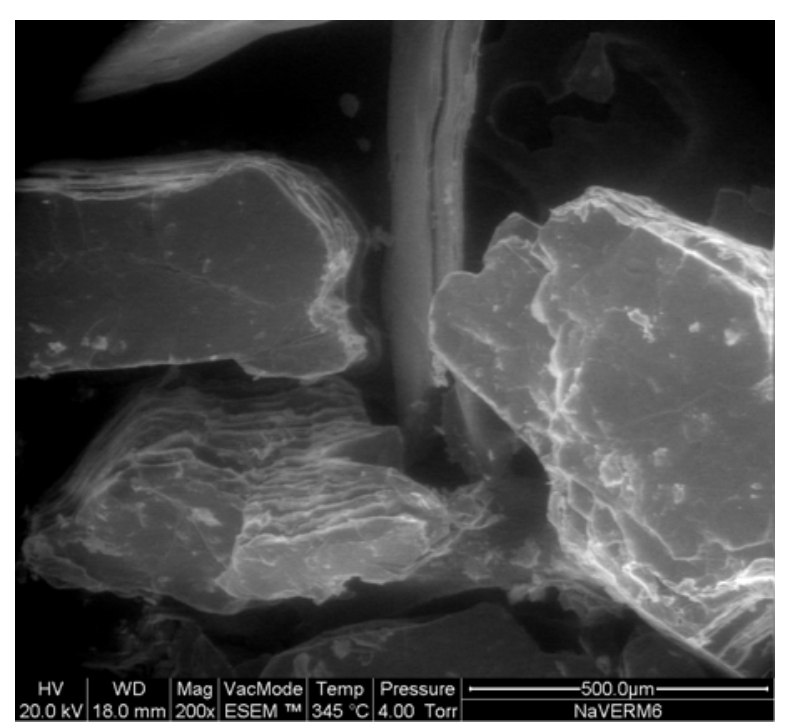

B

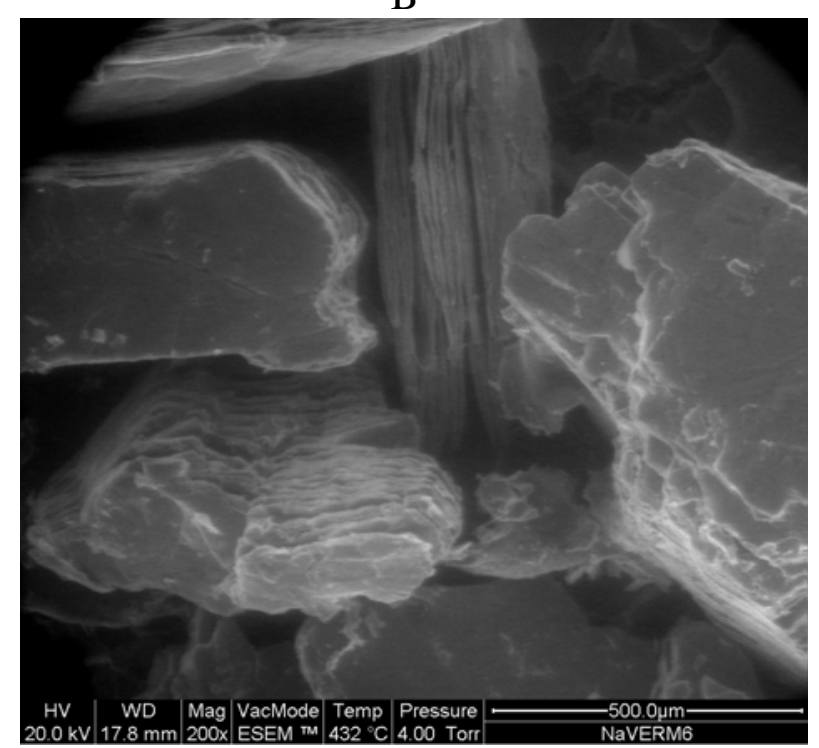

$\mathrm{D}$

Figure 12. ESEM micrographs for the expansion of Superfine grade "vermiculite" treated for six months in brine. A. Just before exfoliation commences at $263^{\circ} \mathrm{C}$; B. and C. During exfoliation at $345^{\circ} \mathrm{C}$ at $367^{\circ} \mathrm{C}$ respectively; and $\mathrm{D}$. After exfoliation at $432^{\circ} \mathrm{C}$. 